\title{
Growth, Consumption and Knowledge Cities
}

\author{
Riccardo Cappellin ${ }^{*}$
}

\begin{abstract}
Cities are important centres of service activities and hubs of new knowledge. The changing structure of production and consumption in post-industrial cities has been analysed by building on the recent economic literature in three related fields, such as: the 'endogenous development' of industrial clusters, the regional development of knowledge intensive business services and the regional factors of innovation and knowledge creation. The increasing interaction between users and producers for the development of new services within cities creates the internal aggregate demand, which is mainly concentrated within cities, and can be a powerful driver of national growth and the new motor or the drivers of the economy in a modern city.
\end{abstract}

Keywords: Growth; Consumption; Knowledge Cities; Innovation; Global Markets

\section{The Increasing Service-Manufacturing Integration in Modern Firms}

Services represent the largest component of total employment at the national level and by far in the largest cities. For example, employment in services accounts for $91.3 \%$ of total employment in London, which has a total population of 7,4 million (Eurostat 2008). The growth of services is to a large extent explained by the fact that industrial firms in the last 40 years have evolved from a strongly vertically integrated 'fordist' model, to a new model of industry where the continuous and fast external change requires innovation, tight specialization and strong integration/cooperation with external firms. Innovation process is characterized by stimulus or obstacles that require not only material investments in new plants and machinery, but also immaterial investments in technical design, $\mathrm{R} \& \mathrm{D}$ and the continuous learning of increasingly qualified human resources.

In particular, knowledge intensive business services (KIBS) promote innovation in the industrial activities (Strambach 2001, 2008; Muller, Zenker 2001; Bryson, Monnoyer 2004; Howells 2006; Wood 2006; Cappellin 2009; Muller, Doloreux 2009; Cappellin 2009), commercial and transport services are needed for managing the transaction costs in the product exchanges (Cappellin 1988), and personal services integrate the industrial goods and represent an increasing share of private

*Full Professor of Economics, University of Rome-Tor Vergata (cappellin@economia.uniroma2.it)

Cappellin Riccardo, Growth, Consumption and Knowledge Cities, Symphonya. Emerging Issues in Management (symphonya.unimib.it), n. 2, 2011, pp. 6-22

http://dx.doi.org/10.4468/2011.2.02cappellin 
consumption. Thus, the new model of industry requires a greater integration of the traditional manufacturing activities with intangible factors, which may be either uphill of the manufacturing phase such as R\&D services or down-hill such as the commercial services. A company's success is conditioned by its ability to manage the system of product intangibles (Brondoni 2010).

Service activities are crucial for the competitiveness of the European industrial firms, as Europe can't compete with emerging economies on the base of lower production costs. Firms in the most developed countries should specialize in the production of 'complex goods', which can't be produced by emerging countries. These products require the integration of many different sectors and technologies together with the use of a highly educated and skilled labour force to respond to the new needs emerging by customers concentrated in the most developed urban areas.

On the other hand, service firms become more similar to industrial ones so that innovation is important in services activities and not only in industrial activities (Gallouj 2002; Gallouj, Weinstein 1997; Howells 2006a; Metcalfe, Miles 2000; Miles 2005; Hipp, Grupp 2005). Service firms are becoming capable to incorporate a service within a good, and increasingly use modern equipment which is produced by industrial firms. In fact, the mass development of modern services in various fields such as communication, health, commercial distribution, media and other, pull the production of many industrial firms and it requires the production of many complementary products, such as ICT and other technical instruments and large public and private investment.

Thus, industry and tertiary sectors become more tightly integrated and that makes impossible a sharp distinction between industry and services firms, as they become more similar. For example, Siemens is about to hive off several divisions into an 'Infrastructure \& Cities' sector. Mr. Löscher, the CEO of Siemens, has branded Siemens a 'green infrastructure giant', emphasizing the German group's roots as a leading innovator and the vast growth potential in supplying infrastructure, such as trams, smart power grids and water treatment facilities, for the ever growing number of megacities around the globe.

\section{The Growth and Evolution of Cities: a Network Approach}

The transformation of the modern economies towards services and the increasing concentration of these latter within cities explain why the process of globalization of firms, markets and knowledge is occurring together with the increasing preference for cities by the most innovative firms and the most qualified workers.

In an industrial economy productions were concentrated either in 'industrial clusters', characterized by the interdependence among many small and medium size firms, or in 'company towns', organized around a large 'fordist' or vertically integrated company. The industrial city (1900-1970) was characterized by the home-to-work commuting, large production plants and machinery and housing, the importance of the exploitation of economies of scale and of modern technologies. Thus, medium and large industrial cities, such as Milano and Torino in Italy, have been characterized by the intense concentration of industrial firms till the end of the 60 s. Later, during the 70 s, the industrial activities started to decentralize to less congested areas. This process contributed to the creation of the well know 
'industrial districts' (Simmie 2005; Capello, Faggian 2005; Cooke 2006) in neighbouring rural areas and it explained the increasing specialization in services by the large and medium size cities.

On the contrary, in a modern economy the increasing role of cities is tightly related to the increasing importance of information and knowledge and to continuous changes, such as new technologies, new productions and new organizational forms. Cities are now at the center of a long term transformation of the industrial economy towards the model of the knowledge economy and new types of services, both for the firms and for the people, are concentrating within cities.

Large firms in scale-intensive sectors, such as automotive, and small and medium size firms in the specialised supplier sectors, such as machine tools, are still important in developed and developing economies, but are moving towards nonurban areas. On the contrary, the increasing role of cities is related to the increasing importance of the following strategic sectors in a modern capitalist system:

- services for individual consumers, which mostly develop in the metropolitan areas where the largest part of the national population is concentrated;

- large collective or network services, such as air and rail transport, telecommunication, energy networks, water networks, which have in largest cities their main nodes in the links with the other non-urban areas;

- financial services, such as banks, stock exchanges, insurance companies, which are concentrated in the global cities where they have an easier access to information;

- high tech firms, which are concentrated in the large city-regions, where there are important universities, research centers and a large pool of a very qualified labor force.

In fact, the move of Siemens, indicated above, underlines how rapidly swelling mega-cities around the world have become much more important for industrial companies and the 600 largest cities account for about half of the world's economic output, a figure that is expected to rise (McKinsey Global Institute 2011).

In a modern economy based on knowledge and innovation the relationships between large multinational companies and the cities where they are located become tighter. Cities are the financial centres where the access to the capital is easier and have a diversified production structure making easier for firms to find specialized suppliers. Cities are the center of the market for new goods and services. Cities are the location of universities, research centers and the residence of that qualified labor force, which is increasingly needed in innovative firms. Qualified workers belong to specialized professional communities, which have in the major cities their hubs, and these workers are also wealthier and more expert consumers, which are more open to the consumption of innovative products. Cities are the center of fairs and markets and the place where it is easier for firms to have access to the specialized information, which are crucial in order to identify new business opportunities. Cities are the centers of the public institutions, which have a great power in promoting the development of new production sectors through appropriate regulations.

The difference between the post-industrial city, which has evolved starting from the 70s, and a traditional industrial city is not represented by the skyscrapers and 
the large office developments, which especially in newly industrialized countries are promoted by a city marketing policy and by famous architects, as the landmarks of the hubris due to a recently achieved industrial strength. The key characteristics of modern cities seem rather to be the increase of the flows and the need to have access to information, as indicated by: a) the mobility during the working time for business meetings and also during the free time for shopping and for social purposes, b) the tight interactions among people needed for the creation of new knowledge both by the firms and by the individual workers and c) the increasing needs for socialization among citizens. A second related characteristic of modern cities is the high diversity of the people, firms and actors, coming from different sectors, cultures and regions and countries.

Thus, in a knowledge economy, the economic and social system of a metropolitan city-region looks like to a 'puzzle' made by disparate information, knowledge, structures, people and also by different policy agendas. As in the story of the Tower of Babel the confusion of languages divides the various groups and may make them unable to understand each other. However, this seeming disorder of the various material, human and immaterial elements, which make a modern city, creates a stimulating environment and pushes the local actors to the continuous search for a harmony, a design or a formal order within the city. The creation of a new order or the intelligent solution of this 'puzzle' requires, on the one hand, the creation of new knowledge, which is the original combination of previous pieces of knowledge. On the other hand, it leads the policy makers to search for a common identity or for some forms of governance or compatibility among the various and often conflicting actors within the urban community, in order to achieve a greater social cohesion, security and well-being.

\subsection{The Creation of New Knowledge and Innovation within Service Activities}

The speed of innovation and the creation of new knowledge play a key role in the creation of new services and the transformation of the urban economy. The city represents a 'regional innovation system' (Cooke 2006), where the process of knowledge creation can be interpreted according to a cognitive-systemic model. Knowledge which is most relevant in service activities is to a large extent tacit (Howells 2002; Asheim, Coenen, Moodysson, Vang 2007), highly localized and linked to a specific context, so it can't be easily transferred.

In particular, the process of innovation and knowledge creation within an urban innovation system can be analysed according to a systemic-cognitive model, called 'territorial knowledge management' (TKM) (Cappellin 2007, 2010, 2011; Cappellin, Wink 2009), which differs from the traditional 'linear model' (Fagerberg 2005; Tidd, Bessant, Pavitt 2005) and also from the more recent 'chain linked' model.

The TKM model does not focus on the innovation process within an individual firm but it highlights that the process of interactive learning leads to the creation of tacit and codified knowledge within networks made by different firms and actors (Cappellin 2003). According to this systemic-cognitive model, the creation of knowledge and the development of innovation can be interpreted as the result of a process of interactive learning, where it is possible to distinguish six drivers or 
phases: a) external stimulus, b) accessibility, c) receptivity-attractivity, d) identity, e creativity and f) governance (Figure 1).

Figure 1: The Systemic/Cognitive Model of Knowledge Creation

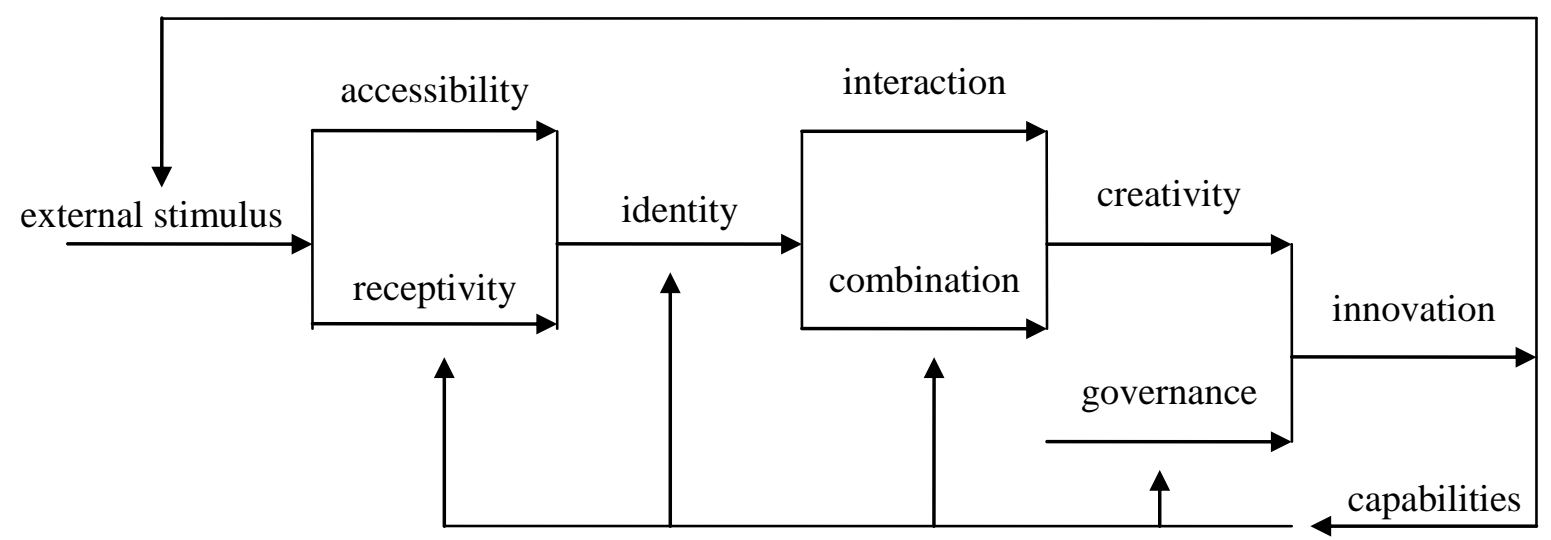

Source: Cappellin, Wink 2009

In fact, the external stimulus to innovate may be induced by a change in the demand or in the pressure of competition, or by a change in technologies. That determines a tension which leads to the search for a solution to the problems of the firm. This search process is facilitated by a lower geographical and/or organizational distance or by a higher 'accessibility' to potential complementary partners (Howells 2002; Cappellin 2003; Boschma 2005; Simmie 2005; Cooke 2006; Karlsson, Andersson 2007). It also requires that these actors are characterized by a low cognitive distance or by an appropriate 'receptivity' or absorption capacity (Cohen, Levinthal 1990). Then, the creation and strengthening of a common 'identity', made by common values, a sense of common belonging, trust relationships, social or relational capital and a high institutional proximity (Nooteboom 2000; Capello, Faggian 2005), represents the prerequisite for cooperation among firms and their search for joint solutions. These new solutions can be identified as the result of 'creativity' (Florida 2002; Morgan 1997; Cappellin 2003), which may be defined as the capability of the various local actors to combine different and complementary pieces of knowledge in an original manner and to interact among them, in the framework of a collective learning process (Lundvall, Johnson 1994). Finally, these new ideas can be translated into economic innovations only when appropriate organizations or institutions (Cooke, Morgan 1998; Hall, Soskice 2001; Kaiser, Prangle 2004; Cappellin 2010) promote a process of multi-level governance or reach formal agreements among various actors, committ appropriate human resources and financial funds and integrate the new ideas with complementary production capabilities.

This process of interactive learning and innovation has a cumulative character, since it improves the capabilities of the individual actors and these capabilities enhance the six factors indicated above. Moreover, the innovation adopted by a firm is changing the external environment for the other firms and it may represent a 
further stimulus leading them to innovate. Thus, interactive learning, knowledge creation and innovation are a dynamic and cumulative process occurring in a urban or regional or national innovation system and also across regions and countries.

\subsection{The Endogenous Process of Development in Cities}

Knowledge is a special good which get not exhausted with the use, while it can develop gradually together with the same use through the original combination of previous knowledge. This process of knowledge creation is enhanced by the spatial contiguity between the various actors. In this perspective, cities enjoy a competitive advantage with respect to rural areas. The large size of the urban economy allows a greater number of consumers and producers and a great variety of consumer preferences and of labor competencies. Cities have a large market and that insures a great variety of potential clients and a great demand for new activities. Many workers and firms are located in a city and that insures the potential use of a large pool of knowledge or competencies.

Moreover, cities are more open to the external world and are more accessible to distant customers or suppliers. That insures an easy access by cities to complementary knowledge and it accelerates the process of innovation within cities.

In particular, knowledge does not affect only the structure of the 'production function' of the firms but also the 'utility function' of the people and it affects both the demand of labour of the firms and the demand of goods by the consumers, as indicated in the model described in Figure 2.

Figure 2: The Process of Urban Growth and the Creation of New Needs and New Skills

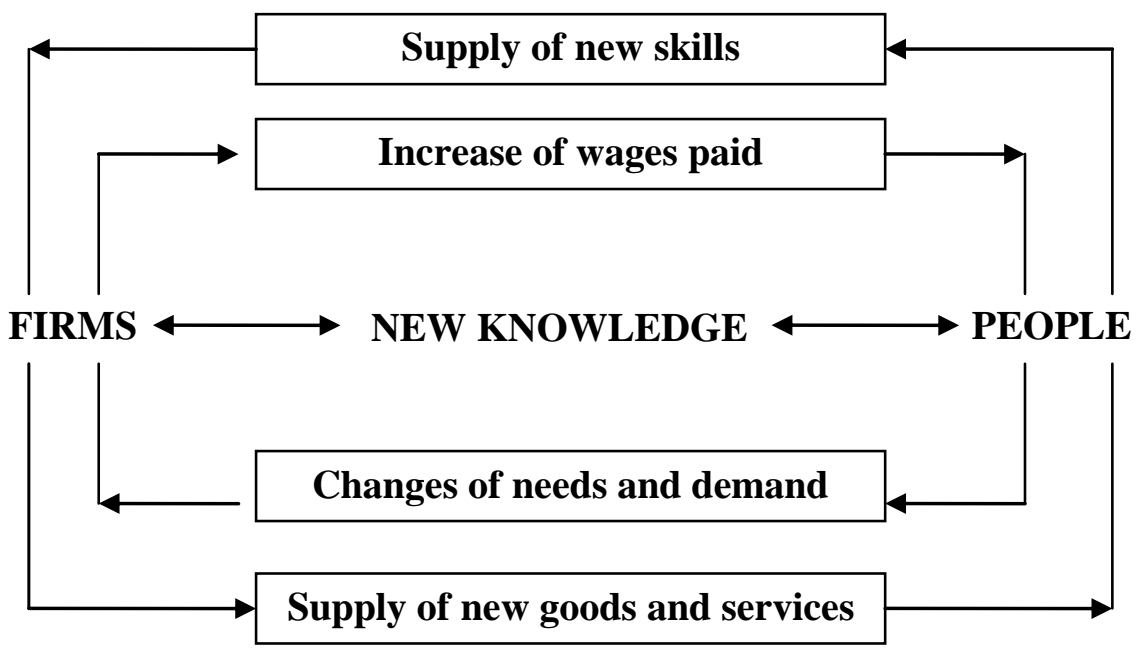

First, a greater knowledge has an impact on the labour market. Firms exploit the new individual competencies of the workers and combine them in order to adopt new production technologies needed for new goods or services as also in order to increase the productivity in the traditional productions. 
New knowledge leads firms to increase the demand for more qualified occupations and leads the households to supply more educated workers to the firms. The greater productivity of the workers leads to an increase of incomes and of the wages paid by the firms to the workers. These higher wages are crucial for creating the additional demand needed by the firms to produce new products and services.

Second, a greater knowledge has also an impact on the markets of goods and services. It leads to the development of new needs and to an increase of the demand for more sophisticated and innovative goods and services.

Firms are stimulated to specialize and to reconvert from the production of traditional products and services to innovative ones. The tight interaction between the various firms, the availability of a qualified labor force within cities and the combination of their respective competencies stimulate the birth of new firms, which often emerge as spin-off from existing firms.

Thus, the process of development in urban areas is based on the one hand on the increasing differentiation of the local consumption and the growth of new needs by the households and by the firms and, on the other hand, on the continuous reconversion of the firm and of the labor force from traditional services to more modern services.

This process of increasing specialization is very similar to the creation of variety and the increasing division of labor through the birth of new firms, which was illustrated by Marshall in the case of the 'industrial districts' made by many small industrial firms or by the modern evolutionary approach which highlights variety creation and market selection.

This process of continuous differentiation of the labor supply and of the production capabilities of the firms together with the differentiation of the pattern of demand by the urban citizens may be defined as a process of 'endogenous growth' (Cappellin 2003; Cappellin, Wink 2009), since it does not depend on the growth of the external demand and on the attraction of investments from other regions and countries. That makes the economic development in modern metropolitan areas different from the export-led urban development of highly specialized 'company towns' during the early industrialization phase of the national economy and also from many small and medium size cities, which base their growth on the attraction of external investments and employers in an increasing globalized economy.

\section{The Role of Consumption within the City Economy}

The traditional economic approach relates the growth of a city economy to the growth of large industrial firms and the exports of industrial products, such as in the case of automobile productions in Torino, Detroit or Paris. On the contrary, the process of economic growth in a city may have an endogenous character, as indicated above, and the internal demand, made by the local investment and consumption of services and goods, may be the driver of the economic growth of a city.

In fact, it is clear that the growth of many cities especially in the phase of the urbanization has been driven by an increase of population and the massive immigration and by the huge investments in construction both in housing and in 
public transport and energy and other infrastructures. In fact, the growth of the construction sector is determined by the demographic expansion of the cities and it has been a major demand stimulus not only for the local but also for the national growth, as it has occurred in China or in India. The construction sector has a weak content of import and then a major multiplier effect on the aggregate urban product. Similarly, the growth of a city in developed economies may be pulled by massive investments related to the organization of major events such as Olympic Games or a large World Expo fair.

Cities are at the center of national and global markets and that allows to the producers a greater access to widely different types of customers and to the citizens the access to a wide scope of potential goods or services to be purchased.

Cities are not only a center of production and of working places, due to the spatial concentration of many firms, but also the living environment for their citizens, since most of the national population in all countries lives in cities.

This evolution of the balance between the production function and the living function of a city explains the change in the relation between the city and its hinterland, where industrial and even service activities and job places are increasingly decentralized. That is indicated by the re-direction of home-to-work commuting flows and by the fact that an increasing number of people do not move to the cities for working, but rather move out of the cities for working and return to the cities for spending their free time. Moreover, many tourists from other regions and countries and people from the surrounding rural areas are attracted to cities for spending their free time and the traffic congestion is increasingly related to the mobility for shopping and social purposes, as it occurs especially during the evening hours and the holiday periods.

The explicit reference to the demand implies to consider a new dimension of the knowledge economy. Knowledge, as indicated above, does not affect only the structure of the 'production function' of the firms but also the 'utility function' of the people. In fact, the knowledge economy is characterized by the development of new needs and life styles leading to the development of the demand of new products and services.

\subsection{Knowledge Workers and New Patterns of Consumption}

Cities and especially large cities are the concentration of the so called 'knowledge workers' (Florida 2002; OECD 2004). Knowledge workers have a different role in the production within the firms, as the knowledge worker should not be considered as a factor of production, which delivers a given work time, but rather as the actor who adds value to the production and contributes to innovation through the management of knowledge within the firm and of the relationships with the suppliers and the clients and other stakeholders external to the firm in the process of interactive learning.

The knowledge workers are characterized by a higher level of formal education and a higher experience and knowledge and by different basic needs, consumption models and by a rather sophisticated demand pattern with respect to the other citizens in an urban area. In fact, the knowledge economy is characterized also by the development of new needs and life styles leading to the development of the demand of new products and services and also to new forms of political behaviour. 
Consumers represent a force of responsible citizens that firms and public authorities can no longer ignore and have new different characteristics (Lambin 2002). Thus, these 'knowledge workers' are also 'knowledgeable consumers' and 'knowledgeable citizens', who are characterized by a greater demand for places where to meet, for travel, transport, use of ICT and media, health services, sport and cultural activities and for centers of education. They demand more environmental quality and energy saving, security from crime, freedom and participation in policy making, social visibility and sometimes also new forms of solidarity. This emerging needs for new services is often related to the lower availability of free time or the increasing value of free time, due to the intense work duties of these workers. In fact, for them, the free time is not completely separated from the working time, as in a traditional 'fordist' organization and the free time plays a crucial role in the social interaction with people sharing the same interests for entertainment and also for career purposes. Thus, knowledge workers usually prefer an urban residence rather than a rural or sub-urban residence that leads to a greater demand and to higher prices of the dwellings in the city centers. Clearly, these new needs and the greater demand for new goods and services represent the stimulus for the creation of new economic activities and of new employment in a modern city.

\subsection{The Integration between Producers and Users within Cities}

Knowledge affects consumer behavior. A 'linear model' of consumer behavior focuses on the adoption of new technologies, while an evolutionary perspective and the network model of innovation focus on the process of interactive learning between the consumer, or the user on the one hand, and the producer on the other hand, and on the need for their higher integration within modern cities. Traditional aggregate growth models do not consider the role of the interaction between the various actors as a factor leading to the development of the demand for new productions. However, recent economic literature highlights seven different forms of tight producer-user interaction.

(1) A first case is indicated by the 'demand led' innovation approach (Fagerberg 2005; Tidd, Bessant, Pavitt 2005), which is important in the industrial supply chains, where 'specialized suppliers', such as in the machine tool industry, adapt their products to the specific needs of their customers.

That producer-user integration is important also in the case of consumer goods. In fact, the consumption of durable goods (such as sport equipment) and also the consumption of non-durable goods (food or music) require that the user devote a considerable period of time to the use of the good or service considered. That leads to the development of specific competencies or tacit knowledge which allows the user to appreciate the quality of the good or service considered. Complex goods create benefits for the consumers only when he/she has the skills needed for appropriately using them and that requires that users develop specific individual competencies, which can be learned only through regular and sometime demanding periods of training and learning, such as in the case of sport equipment, books, music, hi-fi equipment and personal computers.

Moreover, consumption of complex goods and services requires an increasing capability to evaluate the quality of the products or services to be purchased or a 
specific culture of evaluation. In fact, it is increasingly common the case when the firms have to adapt their productions to higher or more demanding consumption standards, such as in the case of entertainment industries, food, clothing, furniture, car production, as the changing and more sophisticated needs of the customers represent a stimulus to innovate going beyond the imitation of competitors.

(2) A second case of tight producer-user integration is indicated by the collaboration of consumers in the production or assembly of final products, such as in the assembly of the IKEA furniture or in the design of new software application for Apple products.

(3) A third important case of tight producer-user integration is that of services activities (Howells 2006; Wood 2006; Strambach 2008; Cappellin 2009; Muller, Doloreux 2009), as services differently from goods require an active role of the user in the production of the service considered. Services, such as management consulting or education services, are 'co-produced' by the supplier and the user, since there are not stocks separating the production and use of a service.

(4) A fourth case of tight producer-user integration is that of 'user innovation' (von Hippel 1994, 2001), such as it occurs in the design of new specialized medical equipment by the doctors themselves and the design of specific sport equipment by the champions in specific sports. In fact, the user may have such important personal specialized needs and may have accumulated such large experience or competencies in a specific activity, to be led to design, self-produce and experiment a specific good or service, eventually with the help of a technologist or a specialized firm. Only later this good or service may be produced by industrial or service firms. This case is similar to that of the so called 'user generated content', such as in the information and knowledge published in on- line technical journals or in tourists blogs. User innovation are the result of 'lead users' which on the one hand anticipate ('lead time') the needs of specific goods and services and introduce new productions and experiment them in pilot projects, and, on the other hand, represent a guide ('leader') for other less experienced users, which consider them a model to be imitated, and that may gradually lead to the creation of a large community of users and producers.

(5) A fifth case of tight interaction between consumers and producers is that of the 'club goods' (Buchanan 1965), which are the activities carried out in specific communities which are voluntary organized by a group of people in order to joint use a specific goods and services. Club goods are a sort of 'public good', where it is possible to hinder the participation of people who do not share the cost of the service but where the use is collective and there is not rivalry in consumption, up to a given limit where congestion may occur. In general, consumers are members of specific communities characterized by similar consumption behavior. In that perspective many consumer goods may be defined as 'club goods'. Specific examples are the cooperatives of consumers or the sport and cultural associations. Consumption is also and most often a social activity, as indicated by the case of housing and food where the measurement unit is the household and not the individual.

The case of 'club goods' clearly implies a geographical dimension, since people in a club should live close to each other to share the same good. Club goods are very important within cities, but even cities and other territorial communities may be defined as a 'club good'. In fact, people who live in a city are willing to pay the 
higher costs which characterize a city, as higher rents, because superior goods and services are available in cities and not in rural areas. Moreover, the citizens choose to live within a given community characterized by the same ethnicity or similar pattern of preferences and they choose to emigrate in search for the most appropriate community.

A typical case of a 'club good' in a city is that of the public transport system, which may have different tariffs for the residents and the no-residents, or that of the cultural and education services, such as universities, which may require the payment of an individual fee to have access to public lectures. Differently from 'public goods', the production of 'club goods' may be left to private companies, which can collect the subscription fees and exploit the economies of scale in production.

(6) A sixth case of tight consumer-producer interaction occurring within cities is that of the 'open innovation' (Chesbrough, Vanharverbeke, West 2006; Chesbrough 2011), which is common in so called 'innovation communities', based on the interaction among users, between user and producers and among producers, as the sharing of knowledge enhances creativity within a specific innovation community and it leads to the development of complex goods and services.

The case of open innovation and innovation communities made by consumers and users is clearly linked to the concept of 'club goods'. In fact, these communities are rather internally homogenous and different from other communities. They are characterized by specific entry barriers, which are not only represented by the price to be paid for the good or the personal income of the consumer but also by specific 'cognitive distances', such as it occurs in the case of the sport or the cultural associations. Thus, the participation to the community is not open to all those willing to pay a price or having a given income and the exclusion from these communities may be determined by localized knowledge or cognitive barriers which define the actors who share the same culture and specific needs and are willing to devote enough time in order to collaborate in their satisfaction.

In fact, knowledge can be considered as a 'club good' rather than a 'public good'. Knowledge on the one hand allows non-rival consumption but on the other hand there are barriers which limit the access to specialized knowledge to those who do not have an adequate education background. The access to this knowledge requires previous tacit cognition which is shared within specific communities. Thus, consumers and producers sharing a common knowledge within specialized communities can be considered as sharing the same 'club good'.

In this perspective, a small local producer, tightly integrated within a specific local professional community, may have a competitive advantage on large multinational firms, as it occurs in the case of the producer of specialized medical or of sport equipment and also in the case of a specialized art gallery. In fact, the participation to a virtual community allows an easier access to localized information and allow to timely identify the new trends suddenly emerging in this community, which we may also call 'demand bubbles' (Gnecchi, Corniani 2003). This localized producer can better identify the specific needs of the individual members of this community and produce together with them a specialized good or service. That reinforces the relationship between the producer and the user and leads to an increasing loyalty of the customers. 
(7) Finally, a seventh case of tight user-producer interaction within cities is that of the 'relational goods' (Becchetti, Pelloni, Rossetti 2008; Gui 2005). These are those goods or services where their use by a person implies the parallel use of the same good or service by another person. Relational goods are produced and consumed at the same time through the participation in some social activity with other people. They respond to the need for socialization of human beings and to the pleasure given by the sharing similar experience with others.

Consumption is a social activity, not only because the joint use allow lower production costs but also because the individual well-being is higher only when consumption is shared. Emerging needs of people and firms have an interactive or collective character. That also corresponds to the simple observation that it makes more pleasure to eat and drink with someone rather than alone. Various new services may be defined as 'relational goods'.

Relational good are those goods and services where the actor takes pleasure in the participation and interaction with other actors, such as in the case of sport activities, friendship relations and the participation to cultural and scientific activities, where reputation is a key incentive. In fact, sometime, the benefit for the consumer is not just the use of a specific product, but rather the access to an immaterial good, such as social alignment or his reputation within the specific community considered.

Thus, consumption is not only related to a monetary exchange between the individual consumer and the individual producer considered, but rather to the complex and changing distribution of individual roles within a specific community, which is interested to the use and or to the production of the considered goods or services. The belonging to a specific community and the adoption of the specific consumption pattern characterizing it, explains the coherence across categories of consumptions, such as food, clothes, housing location, leisure, etc.

Within clusters the actors shares not only goods, services and knowledge but also emotions, a sense of common belonging, a collective identity, various forms of solidarity, which bind them tightly together. The sense of belonging is a typical characteristic of human nature and it responds to the need for security. In fact, cities have first been created in order to defend their inhabitants from external dangers and even today the mass immigration to large cities in developing countries is explained by the possibility to have a better access to vital goods and services, such as food, modern houses, health services and education opportunities.

The case of relational goods highlights that market relations and no-market activities may be tightly related in consumption. The combination between production for the market and self-produced or money free activities, which are undertaken for individual reputation or for solidarity purposes within communities of users, may allow to decrease the production costs of new goods or services and to develop the demand. In fact, it is very common in social services, such as the Red Cross, the fire brigades or the agencies for protection from natural disasters that some workers are paid while others are volunteers. That allows the appearance even in smaller cities of new goods and services, which cannot be produced for the market by specialized private firms. That case is also similar to the case indicated above of IKEA and Apple products, which have succeeded to increase the demand of their product, by combining this latter with the money free activity to be delivered by the user himself. 
These seven cases indicate that cities are characterized by a tight and frequent user-producer interaction. This interaction may stimulate the production of new goods and services and it is clearly important for urban policies aiming to increase overall employment within large metropolitan areas, which are increasingly characterized by large social groups with high structural unemployment.

The growth of the aggregate demand in the actual phase of development of European countries depends on the satisfaction of collective needs by groups of consumers, since these needs have an increasing importance while the demand of products for individual need, such as automobiles, has become saturated.

When many users directly interact, that may lead to the creation of large communities of consumers. However, the development of new goods and services is problematic since they have the nature of a 'club good' or a 'relational good' and no individual actor could alone produce the good or service considered. They require the ex-ante coordination by a specific public or collective actor, which should anticipate the large investment required. In conclusion, the development of new products and services and the creation of new specialized private firms and of new employment require the creation of 'new markets' ('lead markets').

To allow the production of these new goods and services there is the need to exploit economies of scale and overcome threshold. Thus, a highly fragmented demand of many potential users should be aggregated. The different individual needs should be standardized in some respect through a regulation system of the production and use of these goods and services. The definition of common standards and the adoption of procedures, protocols and fiscal measures would allow the interaction, competition and collaboration among various actors and to transform implicit needs into an explicit economic demand, enhancing the creation of new markets and then of new firms.

Even in developed countries, such as European countries, there are many economic needs and production fields which, in a long and medium term perspective, seem still be too little developed and which may represent the opportunity of profitable investment for public and private organizations. Thus, weaknesses in the European cities hint at untapped potentials not only at the local level but also for re-launching national growth. New investments would not only increase the competitiveness of the national economy in the medium term, but also immediately have a positive impact on the aggregate demand and GDP.

A policy agenda for the economic development of urban areas can be based on many new investment initiatives, such as: material and immaterial investments in innovation; investment in research and innovation; launching of large strategic investments organised by networks of firms and greater than the capabilities of individual firms; investments in tertiary education and continuous learning; investments in new employment of young high-qualified workers; enhancement of back-to-work programs for retired people; investments in energy saving in urban buildings and in renewable energies; protection from natural disasters and improvement of the natural environment within cities; development of new healthy nutrition needs and of agro food productions close to urban areas; investments in tourism, cultural activities and activities which are related to the free time; the socialization needs and sports; investments in health and wellness services and development of the social services for an increasingly socially fragmented population; investments in metropolitan and sub-urban rail-links for commuters and 
investments on international air links and in freight rail-transport; enhancement of social services provided by philanthropic and nonprofit organizations; new housing for low income households; improvement of the efficiency and quality of the public services; investments in the fight against organized crime and in the control of corruption in public and private organizations; etc.

A possible conclusion is that investment decisions in modern cities increasingly have a collective nature and individual producers cannot satisfy new emerging needs, but they require a collective, although not always government, provision. A modern economy is increasingly characterized by the importance of 'club goods' and 'relational goods', various forms of knowledge interaction, information asymmetries, conflicts of interest, rents and a large income and wealth inequality. All these factors indicate that a public policy is needed to stimulate investment and the development in a regional and urban economy. Most of these investment can be based on public-private cooperation and imply a different role of the public and the private organization in the design, building and operation phase.

\section{Conclusions and Emerging Issues}

This study has demonstrated that the evolution toward a knowledge economy enhances a change in four related fields of modern metropolitan areas: the labor market, the pattern of consumption, the physical structure of the city and the forms of governance. These changes are the increasing share of 'knowledge workers', the increasing need for new services, 'club goods' and 'relational goods', the increasing mobility and diversity of people and the need for new governance approaches facilitating the coordination of a raising number of different stakeholders.

In a modern knowledge economy, policy strategies for promoting urban competitiveness and growth in large metropolitan areas should be different from the traditional 'export led' strategy usually adopted in smaller industrial cities. The growth of a city does not only depend on the competition in the marketplace among localities for investment. On the contrary, the process of economic growth in a city may have an endogenous character. The internal demand, made by the local investment and the local consumption of services and goods, may be the driver of the economic growth of a city in a modern knowledge economy.

Cities are not only a center of production and of working places, due to the spatial concentration of many firms, but also places of consumption and more generally the living environment for their citizens, since most of the national population in all countries lives in cities.

In particular, this study has illustrated an 'endogenous model' of economic growth in large modern cities, according to which new services develop because of a process of increasing differentiation of the needs of the users and of reconversion of the specialized human capabilities within the firms towards new service productions. This study demonstrates that the urban growth can be determined by the development of the internal demand rather than by the demand of the external markets and it highlights that the new motor or the drivers of the economy in a modern city are the emerging needs of the citizens, rather than the exports. 
Finally, in a policy perspective, this study has indicated various investment fields which correspond to the satisfaction of the new emerging production needs of the firms and to the new living standards of the people. Public policies should aim to create 'new markets' or 'lead markets' by defining common standards and procedures, which allow aggregating the demand of the individual users and transforming implicit needs into an explicit economic demand.

However, the creation of new markets requires a co-ordination at the local level. Cities and regions are more close to people and to firms and can more efficiently than national governments aggregate the local needs and the capabilities of people and firms and stimulate private consumptions and investments. That strategy can't be implemented without a greater role of cities and regions and can't be left only to national governments.

\section{Bibliography}

Asheim B., Boschma R., Cooke P., Constructing Regional Advantage: Platform Policies Based on Related Variety and Differentiated Knowledge Bases, Utrecht University, Urban and Regional research centre, Utrecht, Papers in Evolutionary Economic Geography, vol. 7, n. 9, 2007.

Asheim B., Coenen L., Moodysson J., Vang J., Constructing Knowledge-Based Regional Advantage: Implications for Regional Innovation Policy, International Journal of Entrepreneurship and Innovation, vol. 7, n. 2, 2007, pp. 140-155. http://dx.doi.org/10.1504/IJEIM.2007.012879

Becchetti L., Pelloni A., Rossetti F., Relational Goods, Sociability, and Happiness, Kyklos, vol. 61, n. 3, 2008, pp. 343-363. http://dx.doi.org/10.1111/j.1467-6435.2008.00405.x

Boschma R.A., Proximity and Innovation: a Critical Assessment, Regional Studies, vol. 39, n. 1, 2005, pp. 61-73. http://dx.doi.org/10.1080/0034340052000320887

Brondoni S.M., Intangibles, Global Networks and Corporate Social Responsibility, Symphonya Emerging Issues in Management (symphonya.unimib.it), n. 2, 2010, pp. 6-24. http://dx.doi.org/10.4468/2010.2.02brondoni

Buchanan J.M., An Economic Theory of Clubs, Economica, vol. 32, n. 125, 1965, pp. 1-14. http://dx.doi.org/10.2307/2552442

Capello R., Regional Economics, Routledge, London, 2007.

Capello R., Spatial Transfer of Knowledge in High Technology Milieux: Learning Versus Collective Learning Processes, Regional Studies, vol. 33, n. 4, 1999, pp. 353-65. http://dx.doi.org/10.1080/00343409950081211

Capello R., Faggian A., Collective Learning and Relational Capital in Local Innovation Processes, Regional Studies, vol. 39, n. 1, 2005, pp. 75-87. http://dx.doi.org/10.1080/0034340052000320851

Cappellin R., Transaction Costs and Urban Agglomeration, Revue d'Economie Régionale et Urbaine, n. 2, 1988, pp. 260-278.

Cappellin R., Networks and Technological Change in Regional Clusters, Bröcker J., Dohse D.C., Soltwedel R. (eds.), Innovation Clusters and Interregional Competition, Springer, Berlin, 2003, pp. 52-78.

http://dx.doi.org/10.1007/978-3-540-24760-9_4

Cappellin R., Learning, Spatial Changes, and Regional and Urban Policies: the Territorial Dimension of the Knowledge Economy, American Behavioral Scientist, vol. 50, n. 7, 2007, pp. 897-921. http://dx.doi.org/10.1177/0002764206298316 
Cappellin R., Knowledge Economy and Service Activities, Scienze Regionali, vol. 8, n. 3, 2009, pp. 101-126.

Cappellin R., The Governance of Regional Knowledge Networks, Scienze Regionali, vol 9, n. 3, 2010, pp. 5-42.

Cappellin R., Knowledge Creation and Innovation in Medium Technology Clusters, Karlsson C., Joansson B., Stough R. (eds.), Innovation, Technology and Knowledge, Routledge, 2011, pp. 157184.

Cappellin R. and Wink, R., International Knowledge and Innovation Networks: Knowledge Creation and Innovation in Medium Technology Clusters, Edward Elgar Publishing, Cheltenham, 2009.

Chesbrough H., Open Services Innovation: Rethinking Your Business to Grow and Compete in a New Era, Jossey Bass, San Francisco, 2011.

Cittalia, Fondazione ANCI ricerche, Il Rapporto Cittalia 2009 Città mobili, 2009a, (www.cittalia.it/)

Cittalia, Fondazione ANCI ricerche, I Comuni Italiani 2009, 2009b (www.cislfpsna.it/public/aall/CittaliaIfelComuni2009.pdf)

Cohen W. M., Levinthal D. A., Absorptive Capacity: A New Perspective on Learning and Innovation, Administrative Science Quarterly, n. 35, 1990, pp. 128-152.

http://dx.doi.org/10.2307/2393553

Cooke P., Regional Knowledge Capabilities and Open Innovation: Regional Innovation Systems and Clusters in the Asymmetric Knowledge Economy, Stefano Breschi S., Malerba F. (eds.), Clusters, Networks \& Innovation, Oxford University Press, Oxford, 2006.

Cooke P., Morgan K., The Associational Economy: Firms, Regions and Innovation. Oxford University Press, Oxford, 1998.

http://dx.doi.org/10.1093/acprof:oso/9780198290186.001.0001

European Commission, EUROPE 2020: a Strategy for Smart, Sustainable and Inclusive Growth, Communication from the Commission, 3.3.2010

Eurostat, The Urban Audit - Measuring the Quality of Life in European Cities, General and Regional Statistics, Statistics in focus, 82/2008.

Evans A.W., Urban Economics: An Introduction, Basil Blackwell, Oxford, 1985

Fagerberg J., Innovation. A Guide to the Literature, Fagerberg J., Mowery D.C., Nelson R.R., The Oxford Handbook of Innovation, Oxford University Press, Oxford, 2005, pp. 1-26.

Florida R., The Rise of the Creative Class, Basic Books, New York, 2002.

Gallouj F., Innovation in the Service Economy: the New Wealth of Nations, Edward Elgar, Cheltenham, 2002.

Gallouj F., Weinstein O., Innovation in Services, Research Policy, vol. 26, n. 4-5, 1997, pp. 537-556. http://dx.doi.org/10.1016/S0048-7333(97)00030-9

Gnecchi F., Corniani M., Demand Bubbles, Virtual Communities and Market Potential, Symphonya. Emerging Issues in Management (symphonya.unimib.it), n. 2, 2003, pp. 34-50. http://dx.doi.org/10.4468/2003.2.04gnecchi.corniani

Gui B., From Transactions to Encounters. The Joint Generation of Relational Goods and Conventional Values, Gui, B. and Sugden, R. (ed.), Economics and Social Interaction: Accounting for Interpersonal Relations, Cambridge, Cambridge University Press, 2005. http://dx.doi.org/10.1017/CBO9780511522154.003

Hall P. A., Soskice D. W. (eds.), Varieties of Capitalism: The Institutional Foundations of Comparative Advantage, Oxford University Press, Oxford, 2001. http://dx.doi.org/10.1093/0199247757.001.0001

Hipp C., Grupp H., Innovation in the Service Sector: The Demand for Service-Specific Innovation Measurement Concepts and Typologies, Research Policy, vol. 34, n. 4, 2005, pp. 517-535. http://dx.doi.org/10.1016/j.respol.2005.03.002

Howells J., Tacit Knowledge, Innovation and Economic Geography, Urban Studies, vol. 39, n. 5-6, 2002, pp. 871-884.

http://dx.doi.org/10.1080/00420980220128354 
Howells J., Where to from Here for Services Innovation?, Knowledge Intensive Services Activities (KISA) Conference, Sydney, Australia, March 2006.

Kaiser R., Prange H., Managing Diversity in a System of Multi-Level Governance: the Open Method of Coordination in Innovation Policy, Journal of European Public Policy, vol. 11, n. 2, 2004, pp. 249-266. http://dx.doi.org/10.1080/1350176042000194421

Karlsson C., Andersson M., Knowledge in Regional Economic Growth: the Role of Knowledge Accessibility, Industry \& Innovation, vol. 14, n. 2, 2007, pp. 129-149. http://dx.doi.org/10.1080/13662710701252450

Lambin J.J., Strategic Marketing Revisited after September 11, Symphonya. Emerging Issues in Management (symphonya.unimib.it), n. 1, 2002, pp. 7-27. http://dx.doi.org/10.4468/2002.1.02lambin

Lundvall B.A., Johnson B., The Learning Economy, Journal of Industry Studies, vol. 1, n. 2, 1994, pp. $23-42$. http://dx.doi.org/10.1080/13662719400000002

McKinsey Global Institute, Urban world: Mapping the Economic Power of Cities, March 2011.

Metcalfe J. S., Miles, I. (eds), Innovation Systems in the Service Economy, Kluwer Academic Publishers, Dordrecht, 2000

Miles I., Innovation in Services, Fagerberg J., Mowery D. C., Nelson N. (eds.), The Oxford Handbook of Innovation, Oxford University Press, Oxford, 2005.

Milken Institute, Best-Performing Cities 2011, 2011, (www.milkeninstitute.org/pdf/BPC2011.pdf).

Morgan K., The Learning Region: Institutions, Innovation and Regional Renewal, Regional Studies, vol. 31, n. 5, 1997, pp. 491-504. http://dx.doi.org/10.1080/00343409750132289

Muller E., Doloreux, D., What we Should Know About Knowledge-Intensive Business Services, Technology in Society, vol. 31, n. 1, 2009, pp. 64-72. http://dx.doi.org/10.1016/j.techsoc.2008.10.001

Muller E., Zenker, A., Business Services as Actors of Knowledge Transformation: the Role of KIBS in Regional and National Innovation Systems, Research Policy, vol. 30, n. 9, 2001, pp. 1501-1516. http://dx.doi.org/10.1016/S0048-7333(01)00164-0

Nooteboom B., Learning and Innovation in Organizations and Economies, Oxford University Press, Oxford, 2000.

OECD, Human Resources in Science and Technology, Science and Technology Statistical Compendium, 2004, pp. 21-33, (www.oecd.org).

Simmie J., Innovation and Space: a Critical Review of the Literature, Regional Studies, vol. 39, n. 6, 2005, pp. 789-804. http://dx.doi.org/10.1080/00343400500213671

Strambach S., Innovation Processes and the Role of Knowledge-Intensive Business Services, Koschatzky K., Kulicke M., Zenker A. (eds.), Innovation Networks: Concepts and Challenges in the European Perspective, Heidelberg, Physica, 2001, pp. 53-68. http://dx.doi.org/10.1007/978-3-642-57610-2_4

Strambach S., Knowledge-Intensive Business Services (KIBS) as Drivers of Multilevel Knowledge Dynamics, International Journal Services Technology and Management, vol. 10, n. 2/3/4, 2008, pp. 152-174. http://dx.doi.org/10.1504/IJSTM.2008.022117

Tidd J., Bessant J.R., Pavitt K., Managing Innovation: Integrating Technological, Market and Organizational Change, Hoboken, Wiley, 2005.

Von Hippel E., The Sources of Innovation, Oxford University Press, Oxford, 1994.

Von Hippel E., User Toolkits for Innovation, The Journal of Product Innovation Management, $\mathrm{n}$. 18,2001 , pp. 247-257.

Wood P., Urban Development and Knowledge-Intensive Business Services: Too Many Unanswered Questions?, Growth and Change, vol. 37, n. 3, 2006, pp. 335-361. http://dx.doi.org/10.1111/j.1468-2257.2006.00327.x 